shape of the body, the small eyes, reduced palpi, short, stout appendages, the flattened, club-like antennal funiculi, the peculiar shape of the mandibles and the coloration, all reminiscent of similar characters in the Scolytid and Platypodid beetles, represent so many specialized adaptations to a burrowing life in bark and dead wood. The tribe is, therefore, like certain tribes of Ponerine and Formicine ants and certain vertebrates such as the sturgeons among fishes, the ostriches among birds and the monotremes among mammals, a group of ancient but highly specialized and conservative species which have managed to survive in a narrow, constant environment.

\title{
A NOTE ON THE ASPARAGUS BEETLE, CRIOCERIS ASPARAGI LINN.
}

In the summer of 1928 I examined some small apple trees planted in an asparagus bed in North East, Erie Co.,Pa. Great numbers of the asparagus beetle, Crioceris asparagi Linn., were present on the asparagus, and a large number of both sexes were resting and crawling about on the trunks and branches of the apple trees. Several rows of peach trees were also set in the asparagus bed, but I could find no beetles upon them, although the insects were apparently as numerous on the asparagus between the peach trees as on that between the apple trees. No eggs of the beetle were found on the apple trees, the insects apparently only resting on the trees. Since the beetle is strongly positively phototropic, the fact that the apple trees were open with their branches shaded very little from the sunlight, while the trunks and branches of the peach trees were shaded by foliage, may, perhaps, account for the seeming preference of the asparagus beetle for the apple trees as resting places.

MiltoN F. CROWELL. 

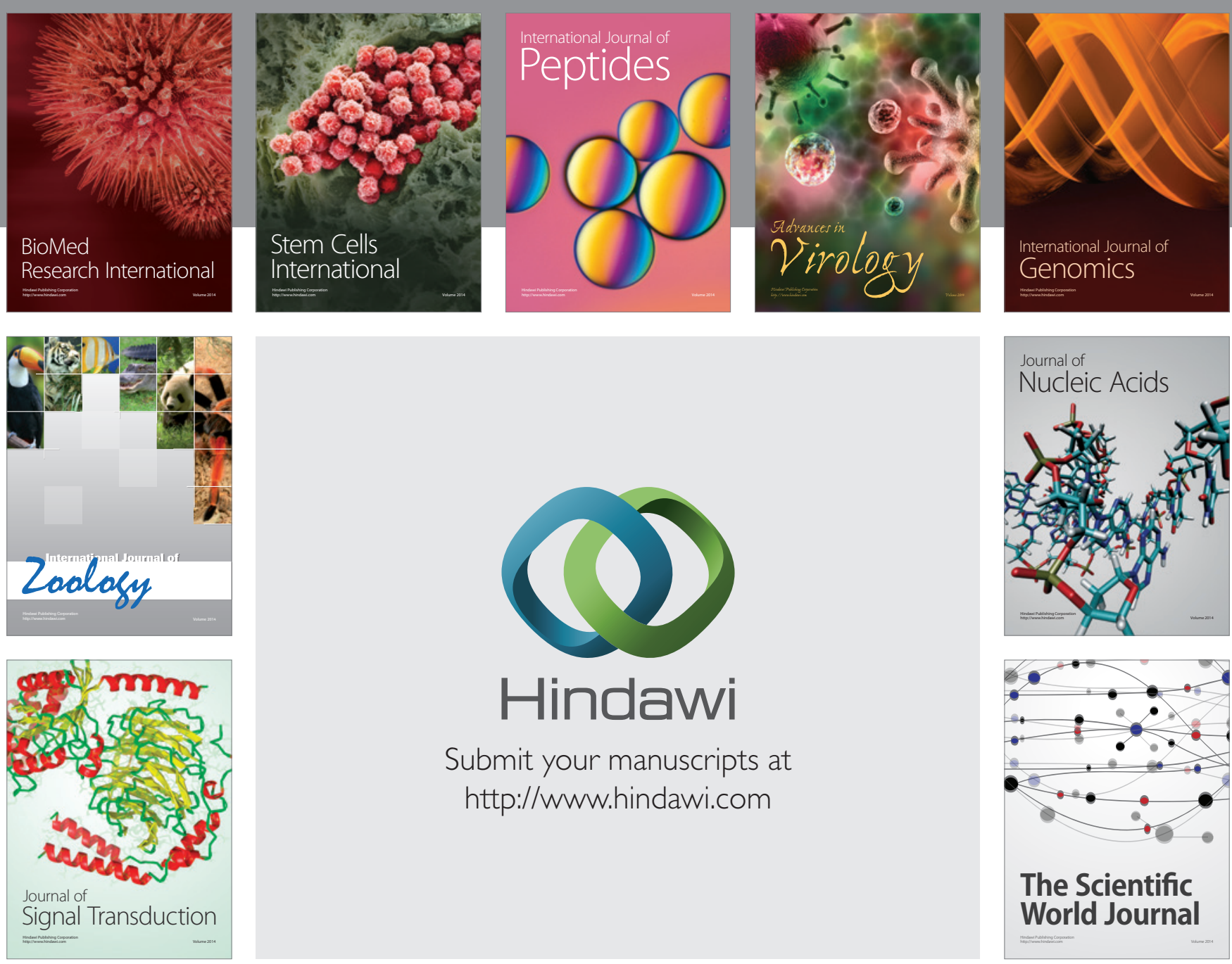

Submit your manuscripts at

http://www.hindawi.com
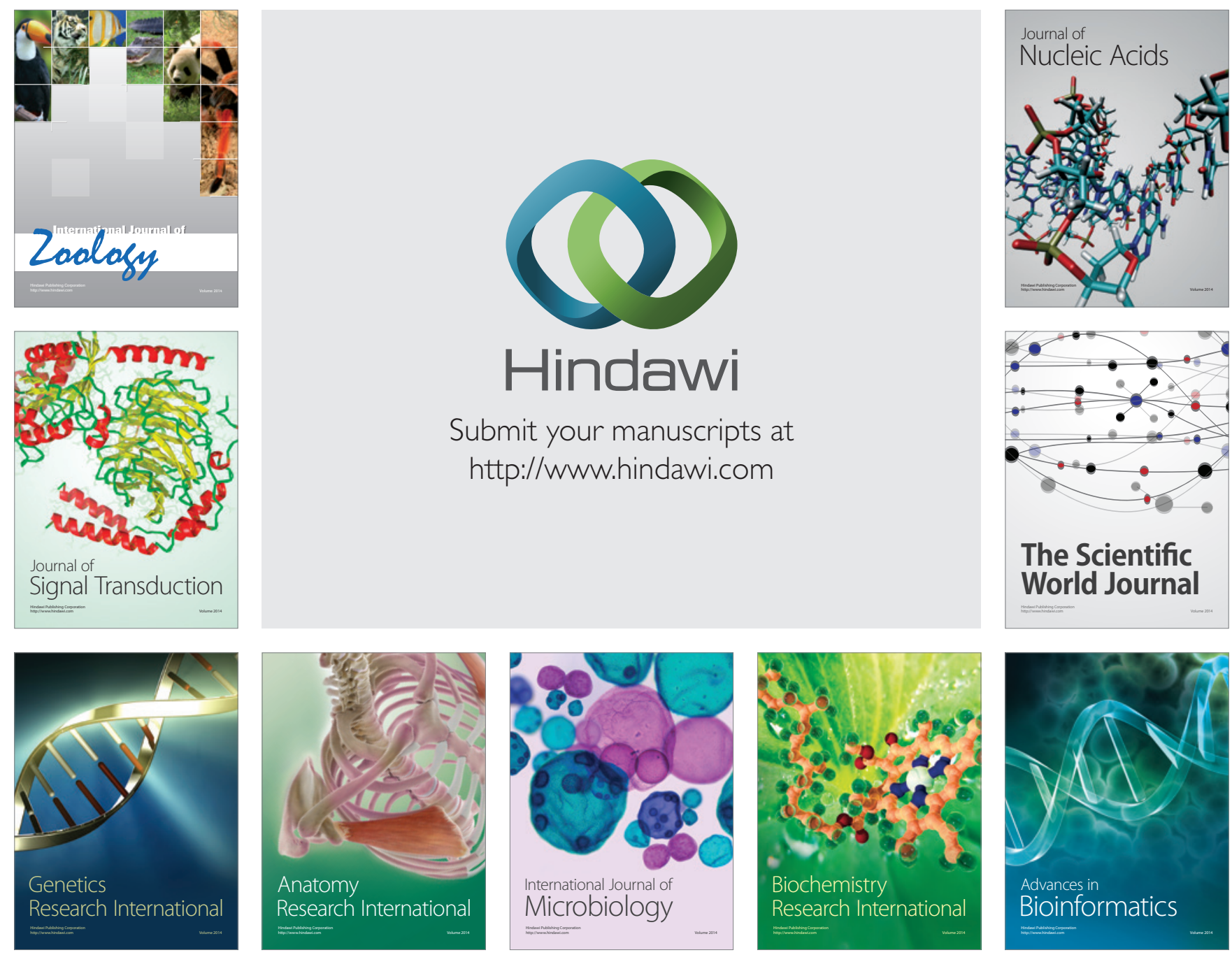

The Scientific World Journal
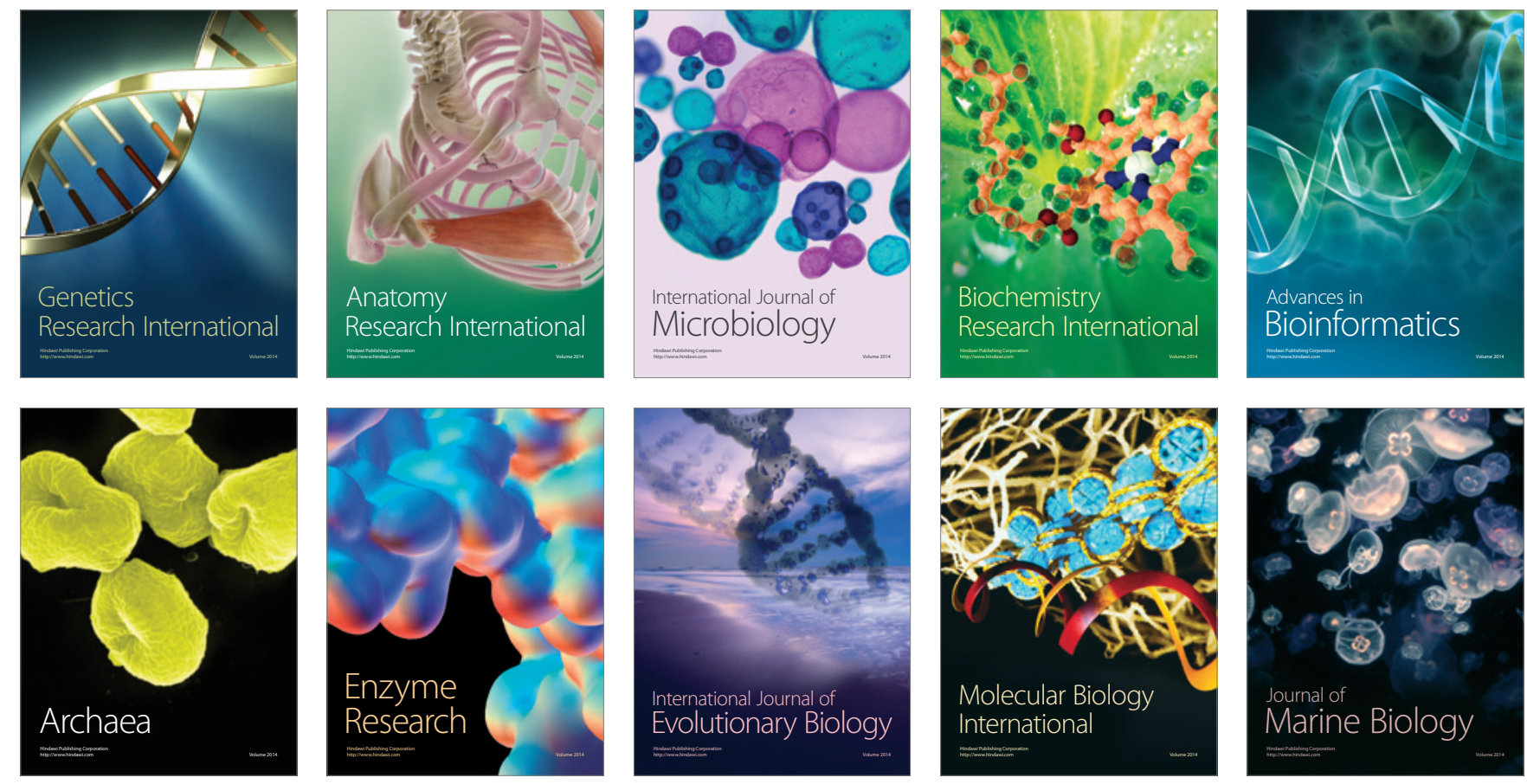